\title{
Injury surveillance and associations with socioeconomic status indicators among youth/young workers in New Jersey secondary schools
}

\author{
Alexsandra A. Apostolico ${ }^{1,2}$ and Derek G. Shendell ${ }^{1,2,3,4^{*}}$ (D)
}

\begin{abstract}
Background: Injuries involving career-technical-vocational education (CTE) are reported to the New Jersey Safe Schools Program online reporting system, the only U.S. State law-based surveillance data for young workers (ages twenty-one and younger), a susceptible, vulnerable adolescent sub-population.

Methods: We examined potential associations between socioeconomic status (SES) indicators and high school student injuries reported between 12/1998-12/2013, excluding injuries acquired by staff members. Associations between DFG score-a proxy for school/district SES - and variables relating to reported injuries, including severity, injury type, injury cause, body parts injured, injury treatment setting and demographics were examined with chi square test $\left(X^{2}\right)$ for independence and logistic regression. To assess potential associations between SES and personal protective equipment (PPE), data were stratified by 2003-2008 and 2008-2013, given mandated payment by employers of PPE for employees.

Results: Statistically significant associations were found between SES and injury cause $\left[X^{2}=(7,14.74), p=0.04\right]$ and SES and injury treatment setting $\left[X^{2}=(1,4.76), p=0.03\right]$. Adjusted odds ratio suggested students from low SES schools were at a higher odds of being treated at a hospital emergency department (ED) than students from high SES schools $(95 \% \mathrm{Cl} 1.3-4.3, p<0.01)$.

Conclusions: These findings indicated low SES schools/districts have increased odds of being treated at ED, after controlling for injury severity. Future research should focus on implications such associations have on health care access and insurance for young workers and their families. With small sample sizes representing lower DFG scoring (SES) schools/districts, additional efforts should be enacted to increase injury reporting in these schools/districts.
\end{abstract}

Keywords: Injury, Socioeconomic status, Young workers

\section{Background}

Unintentional injuries among adolescents are a public health concern for several reasons, including the health impacts on an already susceptible, vulnerable subpopulation (twenty-one and younger) and the multifaceted issues leading to these unintentional injuries. One particular

\footnotetext{
* Correspondence: shendedg@sph.rutgers.edu

${ }^{1}$ Rutgers School of Public Health (SPH), Center for School and Community-Based Research and Education (CSCBRE), 335 George Street -

Suite 2200, New Brunswick, NJ 08903, USA

${ }^{2}$ New Jersey Safe Schools Program, 683 Hoes Lane West, 3rd Floor,

Piscataway, NJ 08854, USA

Full list of author information is available at the end of the article
}

area of concern are injuries involving students in supervised, school-sponsored career-technical-vocational education (CTE) programs, and how socioeconomic status (SES) may relate to the occurrence of these injuries. Currently, there is a wealth of information supporting the association between SES and unintentional injuries among adolescents involving motor vehicle-related injuries, recreational-related injuries, falls, and sports-related injuries [1-4]; however, little is known about the association between SES and work-related injuries in adolescents, specifically injuries among students enrolled in CTE programs. Current literature has suggested an inverse 
association between SES and prevalence of adolescent work-related injuries, where lower SES is associated with a higher prevalence of adolescent work related injuries [5]. Research also has suggested SES influenced how young adults were treated in the work place by employers (e.g., being assigned dangerous tasks and a lack of overall supervision), which can have a direct impact on work place injuries $[6,7]$.

It has been estimated $70-80 \%$ of teens work at some point during their high school career [8]. Because of their inexperience, and in many instances, their lack of knowledge concerning safety and health $(\mathrm{S} \& \mathrm{H})$ topics, young workers have about twice the risk of incurring jobrelated injuries compared to older adults [8-12]. Other factors leading to higher rates of injury among young workers included a lack of physical and/or emotional maturity, lack of proper safety training, being unfamiliar with standard operating procedures for certain tasks, and how young workers maybe not be aware of legal limitations imposed on workers under age 18, including prohibited tasks and prohibited equipment under child labor laws $[8,13,14]$. The highest rates of work-related injuries have occurred in the 18-24 year old bracket, followed by 15-17 year olds [15]. It has been estimated in the United States (U.S.) each year about 160,000 young workers experience occupational related injury or illness; however, the National Institute of Occupational Safety and Health acknowledged how these numbers are widely underestimated and approximately two-third of workrelated incidents are unreported [15].

CTE programs offer a great opportunity to prepare students to enter the work force. It has been estimated there are over 20,000 CTE vocational and ready to work programs in the U.S. [16]. Students in CTE programs are more likely to report having received safety training and having been informed of their legal rights compared to teens working outside of these structured programs $[17,18]$. The U.S. Office of Vocational and Adult Education estimated, on average, every high school student has taken at least one CTE course, and 1-in-4 students have taken three or more courses in a single program area [16]. Clearly, CTE programs encompass a large percentage of young adults. Understanding injuries related to these programs and their association with SES is of public health significance.

Past evidence suggested children of families in the lowest income bracket have the highest rates of unintentional, nonfatal injuries; it is unclear, however, if this association holds true for adolescents enrolled in structured work programs, such as CTE programs [19]. Reducing the prevalence of work related injuries in this subpopulation would improve their $\mathrm{S} \& \mathrm{H}$ and also decrease medical expenditures, as unintentional injuries are a prominent source of medical spending for youth aged 21 years and younger in the U.S. [19].
SES is generally acknowledged as an important predictor of health status [6, 20-22]. Proxies of SES utilized throughout the literature usually encompassed some form of measurement of finance, education, and occupation. SES as it relates to chronic disease [20,23] mental health, $[24,25]$ and infectious disease [26, 27] is relatively well studied; however, further investigation is warranted to examine potential associations between SES and unintentional injuries among young workers. Moreover, a literature review performed by Cubbin et al. in 2002 reported SES was an important predictor of injury; nevertheless, the direction and strength of this association depended on indicators used to measure SES [28-30].

The New Jersey (NJ) Department of Education, based on NJ Administrative Code 6A:19-6.5, requires by law for accidents/incidents (injury or illness) involving CTE students and/or staff that are treated by a licensed physician, physician's assistant, or advanced practice nurse to be reported to the NJ Commissioner of Education [31-33]. These incidents are directly reported to the NJ Safe Schools Program (NJSS) online surveillance system (via Psychdata) for aggregate analyses. Data from submitted individual injury reports are collected on several key variables including reporting county, school district, and school name. Information is also collected on the gender; whether the injured person was a staff or student; the title of the co-op/structured learning experience program; and where the injured person was treated (doctor/clinic versus hospital/emergency department (ED)). Moreover, parts of body injured, nature of injury, cause of injury, severity of injury, use of personal protective equipment (PPE), and date and time of the injury are recorded [31-33].

Here, we examined potential associations between SES indicators and work-related injuries among adolescents, specifically injuries involving CTE programs in the state of NJ, excluding injuries acquired by school staff members. We hypothesized SES would be associated with several key variables examined including injury cause, injury location on the body, injury type, injury severity, use of PPE, where an injury was treated and gender of the injured individual. Specifically, we predicted individuals in lower SES schools/school districts would have more severe injuries, use PPE less often, or use PPE incorrectly compared to higher SES schools/school districts, and have an increased odds of being treated at a hospital. To test this hypothesis, we utilized data collected through the NJSS incident reporting surveillance system between the years 1998-2013 and District Factor Groups (DFG) scores, a proxy of SES [34].

\section{Methods}

This data analysis represents aggregate injury surveillance data; no personal, identifying information was utilized. The Rutgers University-New Brunswick Institutional Review 
Board human subjects approved protocol number is 021997W0383.

In NJ, DFG scores are a proxy used to estimate a community's relative SES, as calculated using six different variables to estimate SES. The variables are: percent of adults with no high school diploma, percent of adults with some high school education, occupational status, unemployment rate, percent of individuals in poverty, and median family income. Data for these variables were collected from the most recent U.S. Decennial Census.

Statistical analyses were conducted within SAS 9.4 (Cary, North Carolina). In order to explore associations between school-district SES indicators and CTE related injuries reported to NJSS, DFG scores were used as a proxy measurement of SES for each reporting school/ school district. Schools were given a DFG score ranging from 1 (lowest score/lowest SES) through 8 (highest score/ highest SES). From the DFG scores, schools were dichotomized into lower scoring (DFG scores 1-4) and higher scoring (DFG scores 5-8) schools. The NJ Department of Education does not assign DFG Scores to county vocational school districts. Therefore, DFG scores were summed and averaged across the county as a whole, and the mean county score was used to assess SES for each reporting school in that county. Descriptive analyses were then performed to describe the demographics of the overall study population, as well as the study population stratified by DFG score. DFG was stratified in two ways, both as raw scores, ranging from 3-6 (for our study population) and as a dichotomous variable either being low (3 and 4 ) or high (5 and 6). This dichotomous classification coincides with low SES and high SES, respectively. Chi square tests $\left(\mathrm{X}^{2}\right)$ for independence were conducted in order to examine associations between SES (high versus low) and various variables including gender, injury-treatment setting (hospital versus doctor/ clinic), injury location on body, injury type, injury cause, severity of injury, and use of PPE, as these variables were hypothesized to be related to SES. Logistic regression was then conducted to further explore associations between SES and injury report variables listed above. Both crude and adjusted models were explored. The adjusted models included several variables hypothesized to potentially confound the association between SES and injury treatment setting. These variables were severity of injury, injury type, body part injured, and injury cause. We further hypothesized how the severity of injury would be the most important predictor of where an injury would be treated, as severity would determine if an injury needed acute attention from the ED, or further care that could be given at a doctor's office; therefore, a preliminary model adjusted solely for severity of injury was examined. To be conservative in the interpretation of results, the final model included adjustments for each of these variables.
To assess potential associations between SES and PPE use, data were stratified by the years 2003-2008 and 2008-2013. This stratification of years was chosen because starting in 2008 employers were legally required to pay for properly selected and fitted PPE determined necessary for employees (NJ as of $2 / 2008$, U.S. as of $10 / 1 / 2008$ ) [35]. PPE usage data were also stratified on career cluster, categorized as either being hazardous or nonhazardous. Categorization of career clusters as hazardous or nonhazardous was based on the 17 non-agricultural hazardous occupations orders (HOs) and 11 agricultural HOs of the U.S. Department of Labor (U.S. DOL) [36]. Based on this classification there were eight career clusters categorized as hazardous: (1) agriculture, food, and natural resources; (2) architecture and construction; (3) transportation, distribution, and logistics; (4) manufacturing; (5) law, public safety, corrections, and security; (6) human services (e.g. cosmetology programs); (7) health sciences; and, (8) science, technology, engineering, and mathematics. Eight career clusters were thus categorized as nonhazardous: (1) marketing; (2) arts, audio/video technology, and communication; (3) business management and administration; (4) education and training; (5) finance; (6) hospitality and tourism; (7) government and public administration; and, (8) information and technology. It should be noted this classification scheme excluded the fact there are hazards present in each career cluster, for example, ergonomic factors which are accounted for in every workplace/workstation environment, including those career clusters classified as non-hazardous.

\section{Results and discussion}

The twenty-one counties in NJ had at least one school district submit an injury report between 1998 and 2013. Sixteen counties were classified as higher DFG scoring schools/districts; nine scored a "6", and seven scored a "5". Five counties were classified as lower DFG scoring schools/districts; four scored a "4" and one scored a "3". Demographic results of the study population are described in Table 1. Overall, there was an even distribution of where an injury was treated, with $56 \%$ being treated at hospitals and $44 \%$ at doctors/clinics. The most common body part injured were fingers, making up 38\% of reported injuries. The most common type of injury was cut/laceration (43\%). The most common injury cause was 'struck by' (35\%). Overall, most injuries reported were nondisabling (68\%); $32 \%$ of injuries were temporarily disabling and there was only one reported permanently disabling injury. In this context, the term temporarily disabling meant the student was able to return to their school-sponsored SLE after medical treatment and rest. Overall, the use of PPE was fairly evenly split- $47 \%$ of reported injuries stated some kind of PPE was in use at the time of the incident. A majority or $95 \%$ of reporting schools were classified as 
Table 1 Summary of descriptive statistics for variables on injury reports to NJ Safe Schools state-law based surveillance, 12/1998-12/2013

\begin{tabular}{|c|c|c|c|c|c|}
\hline Characteristic & Total $(n)$ & Total (\%) & Injury Mode & & \\
\hline DFG & & & Struck Against & 292 & 15.9 \\
\hline 3 & 8 & 0.4 & Caught In/Under/Between & 113 & 6.2 \\
\hline 4 & 87 & 4.5 & Extreme Temperature & 145 & 7.9 \\
\hline 5 & 755 & 39.0 & Other & 451 & 24.6 \\
\hline 6 & 1088 & 56.1 & Rubbed/Abraded & 47 & 2.6 \\
\hline DFG Score & & & Fall (Same Level) & 86 & 4.7 \\
\hline High & 1847 & 95.3 & Struck By & 641 & 35.0 \\
\hline Low & 91 & 4.7 & Multiple & 57 & 3.1 \\
\hline Gender & & & Severity & & \\
\hline Male & 1373 & 71.7 & Non-disabling & 1230 & 68.1 \\
\hline Female & 543 & 28.3 & Temporary disabling & 575 & 31.9 \\
\hline Status & & & Permanent Disability & 1 & 0.1 \\
\hline Student & 1809 & 96.4 & PPE & & \\
\hline Staff & 69 & 3.7 & No & 230 & 47.2 \\
\hline Treatment & & & Yes & 258 & 52.9 \\
\hline
\end{tabular}

Table 1 Summary of descriptive statistics for variables on injury reports to NJ Safe Schools state-law based surveillance, 12/1998-12/2013 (Continued)
Injury Location

Finger

Hand

Eye

Foot

Back

Face

Other

Multiple

Arm

Head

Knee

Ankle

Injury Type

Fracture

Burn

Bruise/Bump

Sprain

Puncture

Other

Multiple

Abrasion

Cut/Laceration

\section{5}

high SES (scores 5 and 6), and 5\% were classified as low SES (scores 3 and 4).

When stratifying by SES (high versus low), the distribution of gender remained similar to the ratio in the overall study population. Males consisted of $72 \%$ of the sample population in high SES schools, and $65 \%$ in low SES schools. When stratified by SES, where injuries were treated differed between high and low SES schools ( $p=$ 0.029). For high SES schools, location of where injuries were treated was fairly evenly distributed-55\% were treated at hospitals and $45 \%$ were treated by doctors/ clinics. On the other hand, in low SES schools, $68 \%$ of injuries were treated at hospitals, while only $32 \%$ were treated by doctors/clinics. Severity of injury did not change substantially when stratified by SES $(p=0.87)$. In high SES schools, $68 \%$ of injuries were non-disabling and $32 \%$ were temporarily disabling. The one reported injury resulting in a permanent disability during the study period, an amputation of fingers, was reported in a high SES school. For low SES schools, 70\% of reported injuries were non-disabling and 30\% were temporarily disabling. For both high and low SES schools, finger was the most common body part injured, 'struck by' the most common cause of injury, and cut/laceration the most common injury type.

Distribution of injury reports and use of PPE were analyzed based on the time period in which they were reported (2003-2008 vs. 2008-2013), as well as whether the injury reported was associated with a hazardous or non-hazardous career cluster (Table 2). We were interested in comparing PPE use in high SES and low SES 


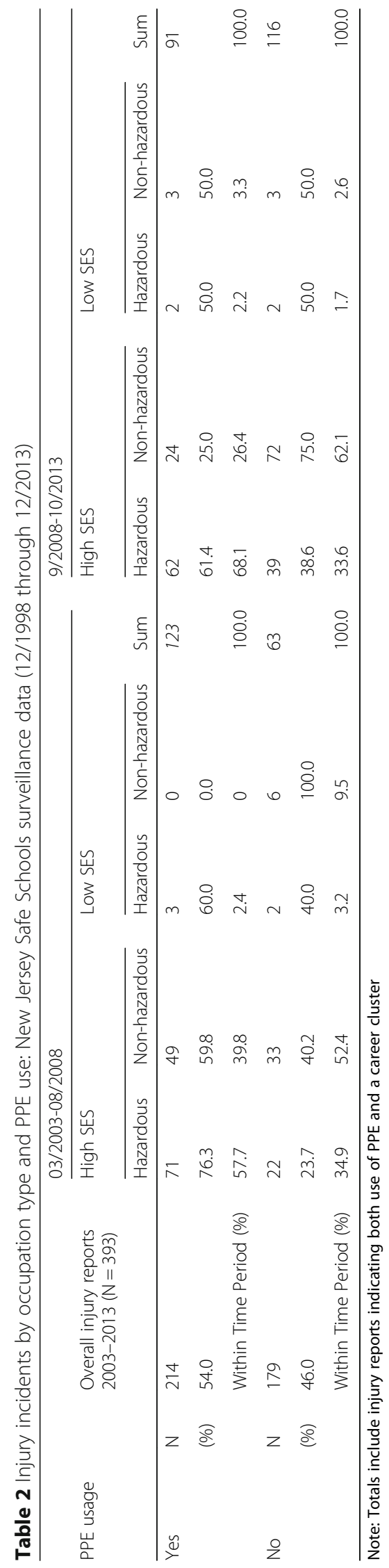


schools. Table 2 depicts results from the PPE use analysis. We observed a trend, where, in general, reported incidents with a response of "Yes" to PPE use decreased from the first time block (2003-2008) to the second time block (2008-2013). And, this trend was observed in general, regardless of hazardous and SES classifications. For example, those reporting "Yes" to PPE use in high SES schools in hazardous career clusters decreased from $76 \%$ to $61 \%$ (71 incidents to 62 incidents) between the two time blocks. An exception to this trend included those incidents among students in low SES schools/districts that reported "Yes" to PPE use in non-hazardous career clusters; however, low cell sizes should be considered. We observed no consistent trend for those who reported "No" for PPE use. In general, the number of incidents in which it was reported "No" for PPE use increased from the first time block (2003-2008) to the second time block (20082013). For example, those reporting "No" for PPE use in high SES schools in hazardous career clusters increased from $24 \%$ to $39 \%$ (22 incidents to 39 incidents) between the two time blocks. We also observed those schools/ districts who reported "No" PPE use in low SES schools in hazardous career clusters remained stable, though cell sizes were low. It should also be noted those who reported "No" PPE use in low SES schools in non-hazardous career clusters decreased by half (from six incidents to three incidents) even if cell sizes were low between years. In summary, as schools/districts which reported using PPE reported fewer injuries than schools/districts which reported not using PPE, these results suggested schools/ districts using PPE are selecting properly fitting PPE and using PPE correctly at a higher rate. Further research is needed for more definitive conclusions on the impact of the state/federal laws requiring purchase of PPE by employers for employees and of specific PPE training. Increase reporting of injuries among low SES schools would also strengthen conclusions.

Descriptive analysis was carried out to better understand associations between SES and injury reports. Chi square test $\left(\mathrm{X}^{2}\right)$ for independence (Table 3) revealed statistically significant associations between SES and injury cause $\left[\mathrm{X}^{2}=(7,14.74), p=0.04\right]$ as well as SES and injury treatment setting $\left[\mathrm{X}^{2}=(1,4.76), p=0.03\right]$. A series of logistic regressions were performed to further examine potential associations between SES and the binary outcome injury treatment setting. To understand the potential differences in treatment locations within each SES group (high versus low), logistic regression was performed comparing the location of treatment in the high vs. low SES schools. Unadjusted odds ratios (OR) suggested low SES schools had an increased odds of being treated at a hospital/ED compared to high SES schools $(\mathrm{OR}=1.75$; 95\% CI =1.1-2.9; Table 4). Similarly, when adjusting for severity of injury, low SES schools still had an increased odds of being treated at a hospital/ED compared to high SES schools (adjusted odds ratio $[\mathrm{AOR}]=1.80 ; 95 \% \mathrm{CI}=$ 1.2-1.9; Table 4). Further, when adjusting for severity of injury, injury type, body part injured and injury cause, low SES schools had an increased odds of being treated at a hospital/ED compared to high SES schools $(\mathrm{AOR}=2.40$; 95\% CI = 1.3-4.3; Table 4).

Previous literature has suggested childhood injuries varied by SES, especially relating to morbidity and mortality [22]. The goal of the present analysis was to better understand potential associations between SES indicators and reported CTE-related injuries. Data reported here represents surveillance data captured between 12/1998 through 12/2013 using the NJSS law-based CTE reporting system, aggregated through Psychdata. We hypothesized SES status would be associated with several key variables including injury cause, injury location on the body, and injury type, injury severity, use of PPE, and where an injury was treated. Specifically, we hypothesized the low SES schools/districts would have more severe injuries, use PPE less often and/or use PPE incorrectly, compared to high SES schools/districts, and have an increased odds of being treated at a hospital/ED.

Statistically significant differences were observed between SES and injury cause. These results suggest a statistically significant association between SES and CTE related injuries and where injuries are treated. For high SES schools, the distribution of injury treatment setting was fairly evenly distributed, with $55 \%$ being treated at hospitals and $45 \%$ being treated by doctors/clinics. In low SES schools, however, a greater difference was observed, with $68 \%$ of injuries being treated at hospitals/ED and $32 \%$ being treated by doctors. Our logistic regression analyses (both crude and adjusted) supported this observation, suggesting low SES schools/districts have increased odds of being treated at a hospital/ED compared to high SES schools/districts. Thus, an argument can be made for the discrepancy between injury treatment setting and SES being in part an issue of access, both in a physical sense (e.g., lack of private/public transportation given distance to travel) and in regards to health care (e.g., number of providers) and/or health care insurance. It should be noted how these data cannot fully capture the recent changes in health care reform, i.e., the passing of the Patient Protection and Affordable Care Act (ACA) in 2010 and its implementation ongoing in 2013 through the present [37]. Future research with NJSS surveillance data may better capture changes in health care status in relation to the ACA. Further research should also be conducted to explain why these discrepancies existed. Current literature has suggested poor individuals who are underinsured or uninsured typically seek care in hospital/ED [38]. It should be noted, however, as these injuries were acquired within school sponsored CTE 
Table 3 High versus low SES schools/districts: injury reports to New Jersey Safe Schools state-law based surveillance, 12/1998-12/2013

\begin{tabular}{|c|c|c|c|c|c|c|c|}
\hline & & & & 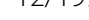 & & & \\
\hline Characteristic & High SESn (\%) & Low SES n (\%) & $p$-value & PPE & & & \\
\hline Gender & & & & Yes & $246(53.2)$ & 15 (55.6) & 0.400 \\
\hline Male & $1,315(72.0)$ & $58(65.2)$ & 0.160 & No & $216(46.8)$ & $12(44.4)$ & \\
\hline
\end{tabular}

Treatment

Hospital

Doctor

Injured Body Part

$\begin{array}{lll}\text { Finger } & 675(37.4) & 47(53.4) \\ \text { Hand } & 191(10.6) & 8(9.1) \\ \text { Multiple } & 180(10.0) & 8(9.1) \\ \text { Arm } & 61(3.4) & 2(2.3) \\ \text { Head } & 53(2.9) & 0(0.0) \\ \text { Knee } & 31(1.7) & 2(2.3) \\ \text { Ankle } & 48(2.7) & 1(1.1) \\ \text { Eye } & 136(7.5) & 7(8.0) \\ \text { Foot } & 68(3.8) & 0(0.0) \\ \text { Back } & 48(2.7) & 2(2.3) \\ \text { Face } & 42(2.3) & 3(3.4) \\ \text { Other } & 273(15.1) & 8(9.1)\end{array}$

Injury Type

Fracture

Burn

Bruise/Bump

Sprain

Puncture

Multiple

Abrasion

Cut/Laceration

Other

Injury Cause

Struck Against

Caught In /Under/Between

Extreme Temperature

Rubbed/Abraded

Fall (Same Level)

Struck By

Multiple

Other

Severity

Non-Disabling

Temporary Disabling

Permanently Disabling

$697(54.9) \quad 49(68.1)$

$572(45.1) \quad 23(31.9)$

0.029

0.140

$64(3.8) \quad 6(6.8)$

$162(9.7) \quad 9(10.2)$

$58(3.5) \quad 2(2.3)$

$85(5.1) \quad 5(5.7)$

$64(3.8) \quad 7(8.0)$

$141(8.4) \quad 9(10.2)$

$43(2.6) \quad 2(2.3)$

724 (43.4) $\quad 34(38.6)$

$330(19.7) \quad 14(15.9)$

$281(16.1) \quad 11(12.6)$

$100(5.7) \quad 13(14.9)$

$137(7.9) \quad 8(9.2)$

$45(2.6) \quad 2(2.3)$

$80(4.6) \quad 6(6.9)$

617 (35.4) $\quad 24(27.6)$

$54(3.1) \quad 3(3.4)$

$431(24.7) \quad 20(23.0)$

$1,168(68.0) \quad 62(70.5)$

549 (32.0) $\quad 26(29.5)$

$1(0.10) \quad 0(0.0)$ 0.039
Table 3 High versus low SES schools/districts: injury reports to New Jersey Safe Schools state-law based surveillance, 12/1998-12/2013 (Continued)

programs, cost incurred would potentially be covered by the reporting school/district. Although this may suggest how health insurance status does not play as vital role in the injury treatment setting of a reported injury, individuals often times do not know how to navigate the health care system, or lack the knowledge concerning reimbursement by reporting school/district. Irrespective of who is responsible for paying for treatment, the cost to society as a whole is vast, with each trip to an ED expecting to cost around $\$ 200.00$ [39]. Moreover, links have been made between workplace $\mathrm{S} \& \mathrm{H}$ and income inequality by the U.S. DOL, which stated workplace injuries may have a greater effect on low wage workers and those trying to enter the middle class. Similarly, U.S. DOL has noted workplace injuries (examined in the adult population) placed burdens on the workers and their families and have contributed to income inequality [40]. Further research may examine how outcomes of workplace injuries affect varying SES grades differently. This analysis explores the association of income inequality and workplace $S \& H$ as it related to students participating in school-sponsored CTE programs. It should also be considered how effect modification may be at play here, skewing the relationship between workplace injury outcomes and SES [41]. There are also areas of improvements regarding the data sources used. The NJ Department of Education should strive to provide direct DFG scores for vocational-CTE schools. A limitation of this study was NJ DFG scores were not available for the twenty-one reporting county-based CTE

Table 4 Odds ratio (OR) for being treated at a hospital emergency department

\begin{tabular}{llll}
\hline Characteristic & OR & $95 \% \mathrm{Cl}$ & $p$-value \\
\hline SES $^{\text {a }}$ & & & \\
High & Referent & & \\
Low & 1.75 & $1.1-2.9$ & 0.03 \\
SES & & & \\
High & Referent & & 0.02 \\
Low & 1.8 & $1.1-3.1$ & \\
SES & & & \\
High & Referent & & $<0.01$ \\
Low & 2.4 & $1.3-4.3$ & \\
\hline
\end{tabular}

${ }^{\text {ac }}$ Crude OR

${ }^{\mathrm{b}}$ Adjusted for severity of injury

${ }^{\mathrm{C}}$ Adjusted for severity of injury, injury type, body part injured, and injury cause 
schools/districts. To overcome this limitation, DFG scores were summed and averaged across reporting schools in each county. These county-average DFG scores were used for each reporting school in each respective county. This limitation may have led to non-differential misclassification bias of exposure-whether the school was reported as a low SES school or a high SES school-and a bias towards the null, i.e., underestimating the true association between SES and where incidents were treated (hospital/ ED versus doctor). Also limiting current analysis was the lower number incident reports from low SES schools compared to high SES schools due to the small number of counties classified as low SES schools. In total, there were 95 injury reports from low SES schools and 1,843 injury reports from high SES schools. Future efforts should be placed on increasing injury reporting in low SES schools.

Another limitation of this study was there were no denominator data-data were reported incidents within CTE programs. There was no information concerning students/staff enrolled in CTE programs that were not injured between the years 1998-2013. Another limitation related to the generalizability of results to the general secondary school/student population. Students enrolled in NJ CTE programs represent a growing yet specific subset of the overall student population. These students may not be generalizable to the general student body throughout NJ, and may not be generalizable to other state CTE students, as CTE programs differ state by state. Another limitation, as is true with most surveillance data, was missing and incomplete data fields. However, as of October 2013, reports are only submitted online to NJSS via Psychdata. This eliminates the ability to leave certain spaces blank as occurred with the past paper based system. Future analyses will compare completeness of reporting factors between the former paper-based and current online reporting system.

This study also had several strengths. This study represented surveillance data over fourteen years for the entire state of New Jersey. These findings add to a major gap in the literature by specifically examining injuries relating to secondary school students enrolled in CTE programs by SES. This study also identified areas to be further analyzed in order to (1) reduce the rates of injures for secondary school students enrolled in CTE programs; (2) reduce total medical expenditures resulting from CTE related injuries; and, (3) improve the overall quality of life for secondary school students enrolled in CTE programs.

\section{Conclusion}

Initial findings from this current analysis suggested there is a statistical difference between high and low SES schools and injury cause, as well as high and low SES schools and injury treatment setting. Results from this analysis suggested injuries occurring in low SES schools have higher odds of being treated at a hospital compared to an injury reported at a high SES school. This association remained true after for controlling for several key variables including injury severity. Future research should explore why this may be the case, and better assess whether this is an issue of medical access, and/or school policy as to where an injury is initially treated. This study's results can guide future development of injury prevention trainings and interventions, which can lead to decreased rates of injuries, decreased medical expenditures, and increased student academic performance and achievements.

\begin{abstract}
Abbreviations
ACA: Patient Protection and Affordable Care Act; AOR: adjusted odds ratio; Cl: confidence interval; CTE: Career and Technical Education; DFG: District Factor Group; DOL: Department of Labor; ED: emergency department/ emergency room; HOs: hazardous occupations orders; NJ: New Jersey; NJ SS: NJ Safe Schools Program; OR: odds ratio; PPE: personal protective equipment; S\&H: safety and health; SES: socioeconomic status; SLE: schoolsponsored structured learning experiences; U.S.: United States.
\end{abstract}

\section{Competing interests}

This paper has not been accepted or published previously and is not under simultaneous consideration for publication except with Environmental Health and Public Health. We have no financial or other non-financial conflicts of interest to disclose. We will transfer copyright.

\section{Authors' contributions}

AAA contributed to the conception and design of this effort and led the data management and analyses, interpretation of results, and the drafting and revising of the manuscript. DGS contributed to the conception and design and assisted in the data analyses, interpretation of results and the drafting and revising of the manuscript. Both authors read and approved the final manuscript.

\section{Author information}

AAA is a Research Teaching Specialist $V$ for the Center for School and Community-Based Research and Education (CSCBRE) and the New Jersey Safe Schools Program (NJ SS) at Rutgers School of Public Health (SPH). As of mid-January 2016, AAA is at University of North Carolina-Chapel Hill Gillings School of Public Health. DGS is an Associate Professor of Environmental and Occupational and Environmental Health at Rutgers SPH and the Environmental and Occupational Health Sciences Institute, Co-Director of CSCBRE, and the Director of NJ SS.

For other papers on NJ SS injury surveillance see: http://www.njsafeschools.org/ papers.html

For more on DGS and CSCBRE and NJ SS, please see the following websites: CSCBRE and NJ SS:

http://sph.rutgers.edu/centers_institutes/community_based_research/index.html http://www.njsafeschools.org

Personal websites including CV content:

http://sph.rutgers.edu/departments/environmental_occupational/faculty_ staff.html [Go to DGS]

http://eohsi.rutgers.edu/eohsi-directory/name/derek-shendell/

http://climatechange.rutgers.edu/people/affiliates/469-shendell-derek

\section{Acknowledgements}

We thank the New Jersey (NJ) Department of Education (NJDOE), Office of Career Readiness (formerly Office of Career and Technical Education) for funding the NJ Safe Schools Program ("Occupational Education and Safety and Health Training and Standards Updating" grant to Rutgers School of Public Health) plus their staff for providing their knowledge and expertise, and other fellow NJ OSHA Alliance for Young Worker Safety and Health members for their support to promote the health and safety of minors. We also graciously acknowledge efforts of other NJ Safe Schools Program staff who have contributed throughout the years.

This paper does not constitute an endorsement of authors, or organizations, by NJDOE. Views and opinions expressed are not necessarily those of the NJDOE. 


\section{Author details}

'Rutgers School of Public Health (SPH), Center for School and Community-Based Research and Education (CSCBRE), 335 George Street Suite 2200, New Brunswick, NJ 08903, USA. ${ }^{2}$ New Jersey Safe Schools Program, 683 Hoes Lane West, 3rd Floor, Piscataway, NJ 08854, USA. ${ }^{3}$ Rutgers SPH, Department of Environmental and Occupational Health, 683 Hoes Lane West, 3rd Floor SPH Building, Piscataway, NJ 08854, USA. ${ }^{4}$ Rutgers University, Environmental and Occupational Health Sciences Institute-Exposure Measurement and Assessment Division, 170 Frelinghuysen Road, Piscataway, NJ 08854, USA.

\section{Received: 13 July 2015 Accepted: 8 February 2016}

\section{Published online: 16 February 2016}

\section{References}

1. Cubbin C, LeClere FB, Smith GS. Socioeconomic status and the occurrence of fatal and nonfatal injury in the United States. Am J Public Health. 2000;90(1):70.

2. Haynes R, Reading R, Gale S. Household and neighbourhood risks for injury to 5-14 year old children. Soc Sci Med. 2003;57(4):625-36.

3. Castillo DN, Landen DD, Layne LA. Occupational injury deaths of 16-and 17-year-olds in the United States. Am J Public Health. 1994;84(4):646-9.

4. Brownell M, Friesen D, Mayer T. Childhood injury rates in Manitoba: socioeconomic influences. Can J Public Health. 2002;93(Suppl. 2):S50-S6.

5. Rauscher KJ, Myers DJ. Socioeconomic disparities in the prevalence of workrelated injuries among adolescents in the United States. J Adolesc Health. 2008;42(1):50-7.

6. Robert SA. Community-level socioeconomic status effects on adult health. J Health Soc Behav. 1998;38(1):18-37.

7. Tannock S, Youth at work. The Unionized Fast-Food and Grocery Workplace. Philadelphia: Temple University Press; 2001.

8. NIOSH Alert: Preventing Deaths, Injuries and IIInesses of Young Workers. Washington, D.C.: National Institute of Occupational Safety and Health U.S. Department of Health and Human Services, 2003.

9. Linker D, Miller ME, Freeman KS, et al. Health and safety awareness for working teens: Developing a successful, statewide program for educating teen workers. Fam Community Health. 2005;28(3):225-38.

10. Schober SE, Handke $J$, Halperin WE, et al. Work-related injuries in minors. Am J Ind Med. 1988;14(5):585-95.

11. Suruda A, Philips $P$, Lillquist $D$, et al. Fatal injuries to teenage construction workers in the US. Am J Ind Med. 2003;44(5):510-4.

12. Hard DL, Myers JR. Fatal work-related injuries in the agriculture production sector among youth in the United States, 1992-2002. J Agromedicine. 2006;11(2):57-65.

13. Laberge $L$, Ledoux É, Auclair J, et al. Risk factors for work-related fatigue in students with school-year employment. J Adolesc Health. 2011:48(3):289-94.

14. Laberge M, Ledoux E. Occupational health and safety issues affecting young workers: A literature review. Work: A Journal of Prevention, Assessment and Rehabilitation. 2011;39(3):215-32.

15. Data Overview of Youth Worker Death and Injuries, United States. National Institute of Occupational Safety and Health - Centers for Disease Control and Prevention, 2011.

16. Schulte PA, Stephenson CM, Okun AH, et al. Integrating occupational safety and health information into vocational and technical education and other workforce preparation programs. Am J Public Health. 2005;95(3):404.

17. Zierold KM, Appana S, Anderson HA. School-sponsored work programs: a first look at differences in work and injury outcomes of teens enrolled in school-to-work programs compared to other-working teens. Occup Environ Med. 2011;68(11):818-25

18. Zierold KM, Anderson HA. Severe injury and the need for improved safety training among working teens. Am J Health Behav. 2006:30(5):525-32.

19. Danseco ER, Miller TR, Spicer RS. Incidence and costs of 1987-1994 childhood injuries: demographic breakdowns. Pediatrics. 2000;105(2):e27-e

20. Winkleby MA, Jatulis DE, Frank E, et al. Socioeconomic status and health: how education, income, and occupation contribute to risk factors for cardiovascular disease. Am J Public Health. 1992;82(6):816-20.

21. Veenstra G. Social capital, SES and health: an individual-level analysis. Soc Sci Med. 2000;50(5):619-29.

22. Macpherson AK, Jones J, Rothman L, et al. Safety standards and socioeconomic disparities in school playground injuries: a retrospective cohort study. BMC Public Health. 2010;10(1):542.
23. Fleischer NL, Roux AVD, Alazraqui M, et al. Social patterning of chronic disease risk factors in a Latin American city. J Urban Health. 2008;85(6):923-37.

24. Aneshensel CS, Sucoff CA. The neighborhood context of adolescent mental health. J Health Soc Behav. 1996:37(4):293-310.

25. Williams DR, Yu Y, Jackson JS, et al. Racial differences in physical and mental health socio-economic status, stress and discrimination. J Health Psychol. 1997;2(3):335-51.

26. Cantwell MF, MCKENNA MT, McCRAY E, et al. Tuberculosis and race/ ethnicity in the United States: impact of socioeconomic status. Am J Respir Crit Care Med. 1998;157(4):1016-20.

27. Cohen S, Doyle WJ, Turner RB, et al. Childhood socioeconomic status and host resistance to infectious illness in adulthood. Psychosom Med. 2004;66(4):553-8.

28. Cubbin C, Smith GS. Socioeconomic inequalities in injury: critical issues in design and analysis. Annu Rev Public Health. 2002;23(1):349-75.

29. Simpson K, Janssen I, Craig WM, et al. Multilevel analysis of associations between socioeconomic status and injury among Canadian adolescents. J Epidemiol Community Health. 2005;59(12):1072-7.

30. Pickett W, Molcho M, Simpson K, et al. Cross national study of injury and social determinants in adolescents. Inj Prev. 2005;11(4):213-8.

31. Shendell DG, Hemminger LE, Campbell JK, et al. Supervising structured learning experiences for students in New Jersey: training teachers in school-based occupational health and safety practice. Public Health Rep. 2009;124 Suppl 1:74.

32. Shendell DG, Jhaveri M, Nowakowski A, et al. Incident surveillance in New Jersey career and technical education programs, 1999 to 2008: attributes, severity, and reported use of personal protective equipment. AAOHN J. 2010;58(9):367-80

33. Shendell DG, Mizan SS, Marshall EG, et al. Cut-laceration injuries and related career groups in New Jersey career, vocational, and technical education courses and programs. Workplace Health \& Safety. 2012;60(9):401-9.

34. District Factor Groups (DFG) for School Districts. Trenton, NJ: New Jersey Department of Education; 2004. (http://www.state.nj.us/education/finance/ rda/dfg.shtml). (Accessed June 19, 2015).

35. Personal Protective Equipment New Jersey Safe Schools Program - Rutgers School of Public Health 2012. (http://sph.rutgers.edu/training/NJ_Safe_ Schools/manual/pdf/Checklist\%2056.PDF). (Accessed June 19, 2015).

36. U.S. Department of Labor. Prohibited Occupations for Non-Agricultural Employees. (http://www.dol.gov/elaws/esa/flsa/docs/haznonag.asp). (Accessed June 18, 2015).

37. Health Care. Washington, D.C.: U.S. Department of Health \& Human Services. (http://www.hhs.gov/healthcare/index.html). (Accessed June 19, 2015).

38. Neighbors HW. Ambulatory medical care among adult black Americans: The hospital emergency room. J Natl Med Assoc. 1986;78(4):275.

39. Malek M, Chang B-h, Gallagher SS, et al. The cost of medical care for injuries to children. Ann Emerg Med. 1991;20(9):997-1005.

40. Michaels D. Adding inequality to injury: the costs of failing to protect workers on the job. 2015. United States Department of Labor-Occupational Safety \& Health Administration.

41. Lee S. Labor relations: On workers' Memorial Day, DOL officials link workplace safety to income inequality. BNA News. 2015:45(18):441-2.

\section{Submit your next manuscript to BioMed Central and we will help you at every step:}

- We accept pre-submission inquiries

- Our selector tool helps you to find the most relevant journal

- We provide round the clock customer support

- Convenient online submission

- Thorough peer review

- Inclusion in PubMed and all major indexing services

- Maximum visibility for your research

Submit your manuscript at www.biomedcentral.com/submit 